\title{
Ultrasonic Cleaner Berbasis Field Programable Gate Array (FPGA)
}

\author{
Achmad Zubair *1, Andani Achmad ${ }^{1}$, Faizal Arya Samman ${ }^{1}$ \\ ${ }^{1}$ Teknik Elektro, Fakultas Teknik, \\ Universitas Hasanuddin Makassar \\ Jl. Perintis Kemerdekaan Km. 10, Tamalanrea Indah, Makassar, \\ *Email: achkmadzubair@gmail.com
}

\begin{abstract}
Abstrak
Pada penelitian ini dibuat pembangkit pulsa ultrasonik dengan menggunakan teknologi FPGA dengan type chip Altera Cyclone IV EP4CE22F17C6N. Pembangkit pulsa ultrasonic sangat diperlukan untuk inspeksi tak merusak menggunakan karena memiliki kelebihan jika dibandingkan dengan sumber radiasi lain, diantaranya: portable (bisa dibawa ke manamana), bahaya radiasi kecil, harga relatif murah, lebih banyak data fisis yang diperoleh, dan penggunaan energi pencatu daya kecil. Tigggi pulsa dan frekuensi gelombang ultrasonik yang diradiasikan pada obyek disesuaikan dengan material yang di radiasi. Pada medium gas diperlukan tegangan pulsa 20 volt, sedangkan untuk material padat ketinggian pulsa pembangkit ultrasonik hingga 350 volt. Lebar pulsa ultrasonik dibangkitkan melalui bahasa pemrograman assembly mikrokontroler tersebut. Pulsa keluaran dikuatkan menggunakan IC Optocoupler agar memperoleh taraf arus yang cukup untuk memicu rangkaian MOSFET IRF832. Rangkaian saklar MOSFET digunakan untuk membangkitkan pulsa tegangan tinggi dan tegangan keluarannya dapat divariasi dari resistor yang dipasang pada kaki Drain. Dari penelitian yang dilakukan diperoleh variasi lebar pulsa yang dapat diatur melalui prosedur permrograman tunda dengan frekuensi keluaran $33 \mathrm{KHz}-48 \mathrm{KHz}$. Dari hasil pengujian kestabilan pulsa diperoleh nilai kestabilan 99,89\% pada lebar 1 us dan $99,07 \%$ pada lebar pulsa $250 \mathrm{~ns}$. Tegangan tinggi pulsa dapat diatur dari 36,8 volt hingga 354,8 volt melalui resistor Drain (RD) dari MOSFET IRF832 yang digunakan. Nilai resitansi dari resistor RD yang digunakan tersebut berada pada kisaran $10 \Omega$ hingga $470 \mathrm{k} \Omega$. Pulsa yang dihasilkan pada rangkaian tersebut dapat menembus material padat yang digunakan sebagai bahan uji.
\end{abstract}

\begin{abstract}
In this research, ultrasonic pulse generator is generated using FPGA technology with Altera Cyclone IV EP4CE22F17C6N chip type. Ultrasonic pulse generators are indispensable for non-destructive inspection uses because they have advantages compared to other radiation sources, including: portable, small radiation hazard, low relative price, more physical data obtained, and energy use Small power supply. Tigggi pulses and ultrasonic wave frequencies radiated on the object adapted to the material in the radiation. In the gas medium required 20 volt pulse voltage, while for the solid material of ultrasonic generator pulse height up to 350 volts. The width of the ultrasonic pulse is generated through the programming language of the microcontroller assembly. The output pulse is amplified using IC Optocoupler to obtain sufficient current level to trigger the IRF832 MOSFET circuit. The MOSFET switch circuit is used to generate high voltage pulses and the output voltage can be varied from resistors mounted on drain feet. From the research, the variation of pulse width can be arranged through delayed programming procedure with output frequency $33 \mathrm{KHz}-48 \mathrm{KHz}$. From the results of testing the stability of the pulse stability value obtained $99.89 \%$ in width 1 us and $99.07 \%$ at 250 ns pulse width. High-voltage pulses can be adjusted from 36.8 volts to 354.8 volts through the Drain (RD) resistors of the IRF832 MOSFETs used. The resistor value of the used RD resistor is in the range of $10 \Omega$ to $470 \mathrm{k} \Omega$. The pulses generated in the circuit can penetrate the solid material used as the test material.
\end{abstract}

Kata-kunci: FPGA, Ultrasonic, Frekuensi, Mosfet,Transducer

\section{Pendahuluan}

Gelombang ultrasonik dapat menembus material padat, cair dan gas. Kecepatan gelombang ultrasonik memiliki kaitan erat dengan besaran fisis dari partikel yang dilalui, diantaranya: jarak, jenis partikel, temperatur, porositas, retakan, modulus elastisitas, modulus young, modulus bulk, dan lain-lain $[1,6]$ Oleh karena itu pengukuran parameter fisis gelombang ultrasonik dapat dilakukan tanpa merusak obyek 
dan memberikan manfaat yang besar terhadap kehidupan sehari-hari.

Pada masa sekarang, metode pengukuran ini disebut dengan NDT (Non-Destructive Test) dan NDE (Non-Destructive Evaluation) [2]. Pada aplikasi NDT dan NDE, gelombang ultrasonik memiliki beberapa kelebihan jika dibandingkan dengan sumber radiasi lain diantara: portable (bisa dibawa ke mana-mana), bahaya radiasi kecil, harga relatif murah, banyak data fisis yang diperoleh, dan penggunaan energi pencatudaya kecil.

Frekuensi gelombang ultrasonik pada media gas sekitar $40 \mathrm{KHz}$, pada penggunaan intensitas tinggi (macrosonic) dan aplikasi di bawah air (underwater acoustic) biasanya memiliki kisaran puluhan kilohertz hingga ratusan kilohertz, sedangkan pada aplikasi medis dan uji material, biasanya menggunakan frekuensi 1 megahertz hingga puluhan megahertz. Bentuk gelombang ultrasonik dapat berupa pulsa (pulse wave) atau gelombang kontinyu (continuous wave) yang disesuaikan dengan metoda pengukuran yang dilakukan. Tigggi pulsa gelombang ultrasonik untuk NDT dan NDE disesuiakan dengan material yang di radiasi. Misalnya pada medium gas diperlukan tegangan pulsa $20 \mathrm{Vpp}$, sedangkan untuk material padat, pulsa ultrasonik hingga $350 \mathrm{~V}$ [3]. Gelombang ultrasonik merupakan gelombang akustik frekuensi tinggi yang tidak mampu didengar oleh telinga manusia. Pada sistem elektronik, gelombang ultrasonik pada umumnya dibangkitkan melalui kristal tipis yang bersifat piezoelektrik. Bahan tersebut bersifat seperti kapasitor dengan konstanta dielektrik tertentu yang memiliki perbedaan muatan listrik dalam lapisannya [4]. Pada keadaan setimbang, total permukaan searah sumbu-y adalah nol. Kemudian pada kristal tersebut diberikan gaya searah sumbu-x (Fx). Maka pada kedua permukaan sejajar sumbu-y terjadi perubahan muatan [5].

Pada dasarnya ultrasonic adalah gelombang suara yang memiliki frekuensi di atas batas pendengaran manusia. Frekuensi batas pendengaran manusia berbeda-beda untuk setiap orang. Namun pada umumnya frekuensi bataspendengaran manusia adalah dari $20 \mathrm{~Hz}-$
$20 \mathrm{kHz}$. Dan gelombang ultrasonic memiliki frekuensi lebih dari $20 \mathrm{kHz}$. Sampai saat ini, frekuensi gelombang ultrasonic telah mencapai 1 $\mathrm{GHz}$ dan jika melebihi frekuensi $1 \mathrm{GHz}$ maka disebut hypersonic

Dalam buku [7] menyebutkan setidaknya ada dua fitur unik yang dimiliki oleh gelombang ultrasonic : Gelombang ultrasonic merambat lebih pelan 100000 kali daripada gelombang elektromagnetik. Hal ini memudahkan untuk memperoleh informasi waktu, variabel delay, dan lain-lainnya pada saat gelombang ultrasonic merambat.Gelombang ultrasonic mudah masuk melewati bahan yang tidak bias dilewati oleh cahaya. Karena gelombang ultrasonic cukup murah, sensitif dan reliabel maka dapat dimanfaatkan untuk mengetahui bentuk gambar topografi dari bahan yang tidak tembus

Pada umumnya sebuah system yang menggunakan ultrasonic cleaner membutuhkan dua komponen dasar utama yaitu ultrasonic generator dan transducers. Ultrasonic generator dipakai untuk membangkitkan sinyal listrik dengan frekuensi di atas $20 \mathrm{KHz}$ sampai dengan $1 \mathrm{GHz}$ dan power tertentu sesuai dengan kebutuhan. Dan transducers dipakai untuk mengubah sinyal listrik dari ultrasonic generator menjadi gelombang mekanik. Transducers memiliki jenis yang berbeda-beda, tergantung dari aplikasinya. Dengan demikian transducers yang dipakai untuk welding akan berbeda dengan transducers untuk cutting, dan pastinya berbeda dengan transducers untuk keperluan cleaner baik frekuensi maupun power driver yang akan diberikan transducers ultrasonic diperlukan untuk merubah energi listrik tegangan bolakbalik menjadi gelombang ultrasonic. Secara umum ada dua jenis tipe transducers ultrasonic yaitu magnetorestrictive dan piezoelectric.

Dalam sistem pembersihan dengan ultrasound, yang melakukan pekerjaan menghilangkan kontaminan dan menjagaMereka jauh dari substrat (biasanya dengan bantuan kimia) adalah dua fenomena propagasi Suara dengan intensitas tinggi: Cavitation dan momentum transfer. Perilaku makroskopis fenomena ini dalam proses pembersihan [8] adalah dispersi, erosi dan gelembung 
Beberapa lain yang berhubungan dengan sistem ultrasonic cleaner adalah penelitian yang berhasil dapat menghasilkan inverter ultrasonic dengan efisiensi tinggi yang bisa menggerakkan reaktor kavitasi akustik dengan daya $2 \mathrm{~kW}$ frekuensi kerja $10 \mathrm{Khz}$ dan $100 \mathrm{kHz}$ [9] dan pada penelitian [10] menghasilkan pembangkit gelombang ultrasonic dengan menggunakan mikrokontroller At-Tinny 2313.

\section{Deskripsi Permasalahan}

Mengingat sistem ultrasonic cleaner cakupannya sangat luas dan setting point besaran frekuensi yang berbeda menurut fungsinya masing-masing, maka penulis akan melakukan penelitian dengan batasan-batasan sebagai berikut :

1. Perancangan pembangkit gelombang ultrasonic yang dibangkitkan hanya dibatasi pada frekuensi $37 \mathrm{KHz}$ sampai dengan 44 $\mathrm{KHz}$ dengan mode pemilihan menggunakan selector switch

2. Power driver output maksimum sebesar 100 Watt.

\section{Hasil Perancangan}

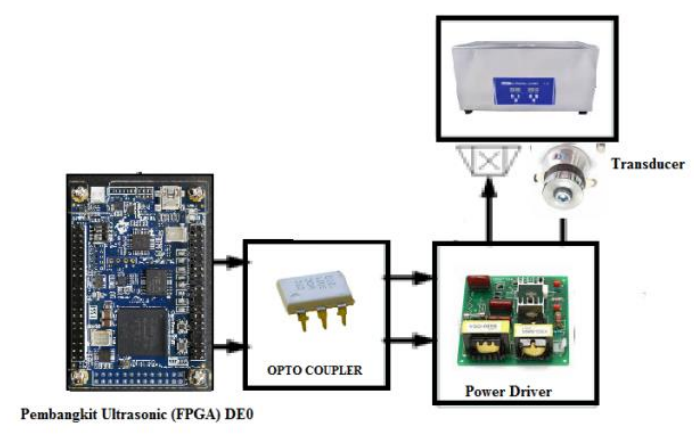

Gambar 1. Perancangan Sistem

Pada Gambar 1 terlihat rancangan sistem keseluruhan yang terdiri atas FPGA sebagai komponen pembangkit frekuensi Optocoupler sebagai interface dengan power driver serta 2 buah transducer ultrasonic $40 \mathrm{Khz}$ dengan masing masing daya 50 Watt. Sistem yang dirancang terdiri dari beberapa bagian yaitu perancangan hardware (perangkat keras) maupu software (perangkat lunak). Secara umum diagram blok sistem ultrasonic cleaner terlihat seperti pada Gambar 1 Bagian utama dari ultrasonic generator adalah Sebuah FPGA dengan menggunakan chip Altera Cyclone IV EP4CE22F17C6N pada DEO-Nano Board.

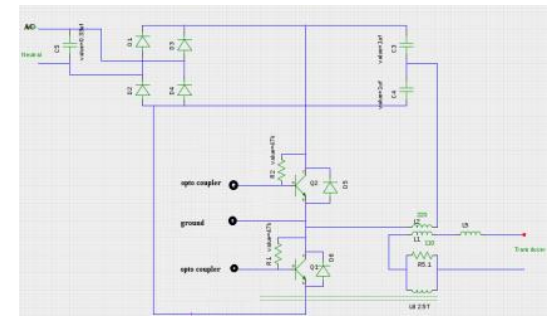

\section{Gambar 2. Perancangan power driver ultrasonic} cleaner

Pada Gambar 2 terlihat schematics diagram dari power driver ultrasonic cleaner dimana transistor MJE 13007 sebagai penggerak saklar untuk tegangan tingginya bagian lainnya adalah transformator arus dan transformator frekuensi yang mengahsilkan tingkat penguat yang akan menghasilkan tegangan dan arus serta frekuensi yang dibutuhkan oleh beban selanjutnya bagian yang lain adalah sebuah transducer yang terbuat dari bahan piezoelectric

Selanjutnya rancangan sistem adalah peancangan software pembangkit sinyal ultrasonic cleaner yang menggunakan software quartus. Quartus merupakan sebuah software yang digunakan untuk membuat simulasi rangkaian logika secara digital dengan memanfaatkan bahasa deskripsi yaitu VHDL ataupun Verilog. Sebenarnya tidak hanya Quartus yang dapat digunakan untuk membuat simulasi rangkaian logika digital, namun ada beberapa software lain yang dapat digunakan, contohnya adalah Xilinx, Multisim, Model-Sim dan sebagainya. Quartus sendiri merupakan software yang dibuat oleh sebuah perusahaan yang bernama Altera (dapat diakses www.altera.com untuk infomasi lebih mendalam). Pada praktikum teknik digital ini software Quartus 2 versi 11.1 (Gambar 3) yang akan digunakan. Melalui software Quartus ini, nantinya hasil pengkodean dapat diload ke dalam FPGA agar dapat dilihat hasilnya secara fisik atau real. 


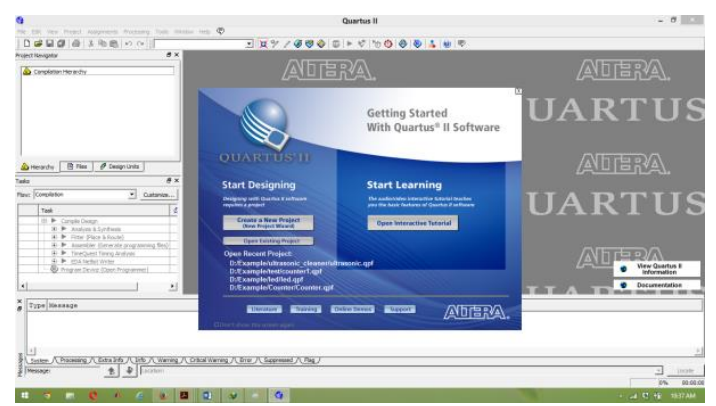

Gambar 3. Tampilan software quartus ver 11

Terlihat Pada Gambar 4 perancangan software yang berbasis hardware yang biasa disebut HDL (Hardware Decription Language) mempunyai input frekuensi yang berbeda tergantung kebutuhan dan dikendalikan oleh beberapa switch yang merupakan pengendali bit yang akan ditampilkan

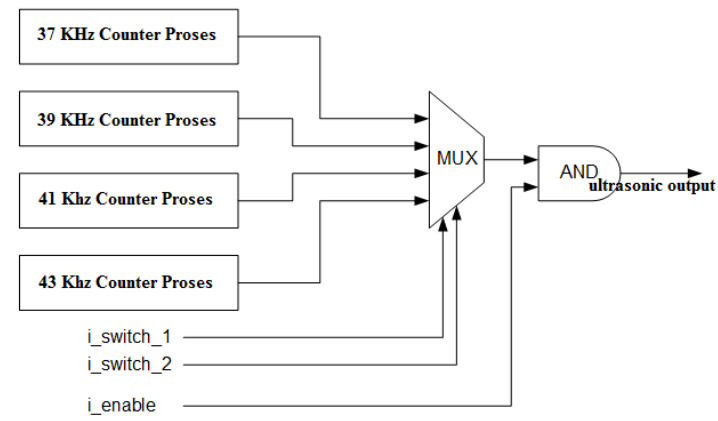

Gambar 4. Perancangan software

Berikut ditampilkan potongan program Quartus (VHDL):

library ieee;

use ieee.std_logic_1164.all;

use ieee.numeric_std.all;

entity ultrasonic is

port (

i_clock : in std_logic;

i_enable : in std_logic;

i_switch_1 : in std_logic;

i_switch_2 : in std_logic; i_switch_3 : in std_logic;

o_led_drive : out std_logic

);

end ultrasonic;

architecture rtl of ultrasonic is

-- Rumus Formula:

-- Formula is: (25) MHz / $100 \mathrm{~Hz} * 50 \%$ duty cycle)

-- So for $100 \mathrm{~Hz}$ : $25,000,000 / 100 * 0.5=125,000$

constant c_CNT_37KHZ : natural :=676;

constant c_CNT_38KHZ : natural $:=658$;

constant c_CNT_39KHZ : natural :=641;

constant c_CNT_40KHZ : natural $:=625$;

constant c_CNT_41KHZ : natural :=610;

constant c_CNT_42KHZ : natural $:=595$;

constant c_CNT_43KHZ : natural :=581;

constant c_CNT_44KHZ : natural := 568;

-- These signals will be the counters: signal r_CNT_37KHZ: natural range 0 to c_CNT_37KHZ;

signal r_CNT_38KHZ : natural range 0 to c_CNT_38KHZ; signal r_CNT 39KHZ : natural range 0 to c CNT 39KHZ; signal r_CNT_40KHZ : natural range 0 to c_CNT_40KHZ; signal r_CNT_41KHZ : natural range 0 to c_CNT_41KHZ; signal r_CNT_42KHZ : natural range 0 to c_CNT_42KHZ; signal r_CNT_43KHZ : natural range 0 to c_CNT_43KHZ;

signal r_CNT_44KHZ : natural range 0 to c_CNT_43KHZ;

-- These signals will toggle at the frequencies needed: signal r_TOGGLE_37KHZ : std_logic := '0'; signal r_TOGGLE_38KHZ : std_logic := '0'; signal r_TOGGLE_39KHZ : std_logic $:=' 0$ '; signal r_TOGGLE_40KHZ : std_logic $:=$ ' 0 '; signal r_TOGGLE_41KHZ: std_logic : $=$ ' 0 '; signal r_TOGGLE_42KHZ : std_logic $:=$ ' 0 '; signal r_TOGGLE_43KHZ : std_logic : : ' 0 '; signal r_TOGGLE_44KHZ : std_logic := '0';

-- One bit select wire.

signal w_LED_SELECT : std_logic; signal temp: std_logic_vector(0 to 7);

begin

p_37_KHZ : process (i_clock) is

begin

if rising_edge(i_clock) then

f r_CNT_37KHZ = c_CNT_37KHZ-1 then -- -1 ,

r_TOGGLE_37KHZ $<=$ not r_TOGGLE_37KHZ;

r_CNT_37KHZ $<=0$;

else

r_CNT_37KHZ $<=$ r_CNT_37KHZ + 1;

end if;

end if;

end process $\mathrm{p}$ _37_KHZ;

p_38_KHZ : process (i_clock) is

begin

if rising_edge(i_clock) then

if $\mathrm{r}$ CNT $38 \mathrm{KHZ}=\mathrm{c}$ CNT $38 \mathrm{KHZ}-1$ then ---1

r_TOGGLE_38KHZ $<=$ not r_TOGGLE_38KHZ;

r_CNT_38KHZ $<=0$;

else

r_CNT_38KHZ $<=$ r_CNT_38KHZ +1 ;

end if;

end if;

end process $\mathrm{p} \_38 \_\mathrm{KHZ}$;

-- Create a multiplexor based on switch inputs

w_LED_SELECT $<=$ r_TOGGLE_37KHZ when (i_switch_1 = '0' and i_switch_2 = '0'and i_switch_3 = ' 0 ') else

r_TOGGLE $38 \mathrm{KHZ}$ when (i_switch $1=$ ' 1 ' and i_switch $\_2=$ ' 0 'and i_switch_3 = '0') else

r_TOGGLE 39KHZ when (i_switch $\_1=$ ' 0 ' and i_switch $\_2=$ ' 1 'and

i_switch_3 = '0') else

r_TOGGLE 40KHZ when (i_switch $11=$ ' 1 ' and i_switch $\_2=$ ' 1 'and

i_switch_3 = ' 0 ') else

r_TOGGLE $41 \mathrm{KHZ}$ when (i_switch $\_1=$ ' 0 ' and i switch $\_2=$ ' 0 ' and

i_switch_3 = '1') else

r_TOGGLE 42KHZ when (i_switch 1 = ' 1 ' and i_switch $\_2=$ ' 0 'and

i_switch_3 = '1') else

r_TOGGLE_43KHZ when (i_switch_1 = '0' and i_switch_2 = '1'and

i_switch_3 = '1') else

$--)$.

o_led_drive $<=$ w_LED_SELECT and i_enable; end rtl;

\section{Hasil Simulasi}

Pengujian sistem pembangkit sinyal ultrasonik berbasis FPGA dengan menggunakan 
metode pembagian $1 / 2$ duty cycle dari frekuensi crystal yang digunakan FPGA atau menggunakan rumus $1 / 2$ frekuensi FPGA / frekuensi yang diinginkan $\mathrm{x} \quad 0.5=$ hasil frekuensi untuk mengamati hasil penelitian dibutuhkan alat sebagai berikut :
1. Oscilloscope Digital merk Gws Instek G05 $1102 \mathrm{~A}$

2. Multimeter merk Sanwa Type CD800a

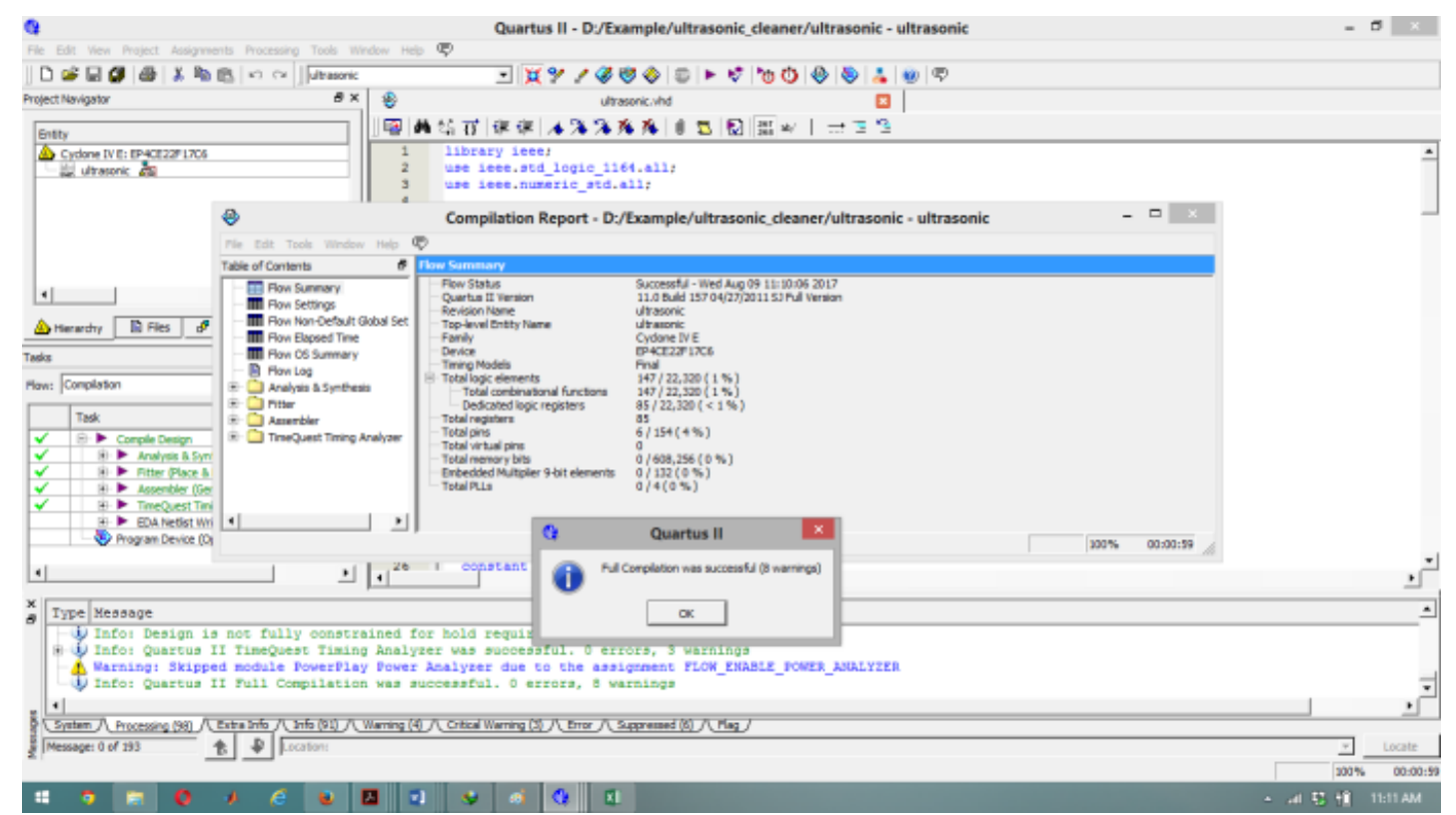

Gambar 5. Hasil Compile VHDL

Hasil Compile menggunakan FPGA cyclone IVe dan processor EP4CE22F17C6 maka terdapat elemet logic 147 dan 85 logic register dan memory bit $0 / 608,256$ ( $0 \%$ ) sesuai dengan Gambar 5. Dari hasil perancangan Pembangkit sinyal maka didapatkan sesuai dengan gambar sesuai Tabel 1 berikut :

Tabel 1. Pengukuran frekuensi

\begin{tabular}{cccccc}
\hline $\begin{array}{c}\text { Crystal/ } \\
\text { Natural } \\
(\text { KHz })\end{array}$ & $\begin{array}{c}\text { Output } \\
\text { Freq } \\
(\text { KHz) }\end{array}$ & $\begin{array}{c}\text { Duty } \\
\text { Cycle }\end{array}$ & Formula & $\begin{array}{c}\text { Hasil Pengukuran } \\
\text { Oscilo } \\
\text { scope }\end{array}$ & $\begin{array}{c}\text { Multi } \\
\text { meter }\end{array}$ \\
\hline 50 & 37 & 0.5 & 675.7 & 36.98 & 36.97 \\
\hline 50 & 38 & 0.5 & 657.9 & 37.99 & 38.99 \\
\hline 50 & 39 & 0.5 & 641.0 & 39.01 & 38.99 \\
\hline 50 & 40 & 0.5 & 625.0 & 39.99 & 39.99 \\
\hline 50 & 41 & 0.5 & 609.8 & 40.98 & 40.97 \\
\hline 50 & 42 & 0.5 & 595.2 & 42.16 & 42.02 \\
\hline 50 & 43 & 0.5 & 581.4 & 43.08 & 43.02 \\
\hline 50 & 44 & 0.5 & 568.2 & 44.15 & 44 \\
\hline
\end{tabular}

Hasil penelitian yang dilakukan diperoleh variasi lebar pulsa yang dapat diatur melalui prosedur permrograman tunda dengan frekuensi keluaran $33 \mathrm{KHz}-48 \mathrm{KHz}$. Dari hasil pengujian kestabilan pulsa diperoleh nilai kestabilan 99,89\% pada lebar $1 \mathrm{nS}$ dan 99,07\% pada lebar pulsa $250 \mathrm{nS}$. Tegangan tinggi pulsa hasil dapat dilihat pada Osciloscope sesuai Gambar 6.

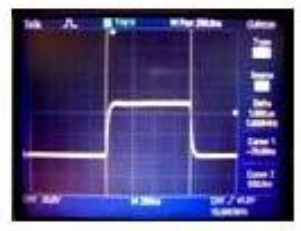

(a)

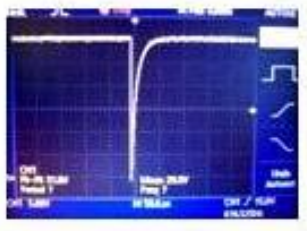

(b)
Gambar 6. Bentuk Pulsa Eksitasi FPGA(a) Keluaran Penguat Pulsa IRF840(b)

\section{Kesimpulan}

Dari hasil penelitian dan analisa yang telah dilakukan, disimpulkan bahwa sistem ultrasonic cleaner dapat bekerja dengan baik untuk membersihkan material terutama benda padat seperti besi, emas, baja untuk material yang berbentuk kain belum optimal karena timbulnya panas berlebihan, Ultrasonic ini bekerja cukup baik dikisaran 10 menit saja. 
Saran pada penelitian ini adalah dibutuhkan rancangan power driver yang lebih handal yang dapat bekerja secara optimal dan lebih hemat konsumsi daya.

\section{Referensi}

[1] Deidda, G.P., and Ranieri, G., 2006. Seismic tomography imaging of an unstable embankment, Journal of Engineering Geology. Volume 82, Issue 1, Pages 32-42.

[2] Krautkamer J. And Krautkramer. H.1990. Ultrasonic testing of material. Spangel Verlag. New York

[3] Rahim, R. A., et al., 2007. Non-invasive imaging of liquid/gas flow using ultrasonic transmission-mode omography. Sensors and Actuators A, vol. 135, pp. 337-345

[4] McDicken, W.M, 1990. Diagnostic Ultrasonic, Principles and uses of Instrument. Willey and
Sons, New York.

[5] Fraden, J., 1996. Handbook of Modern Sensors : Physics Designs, and Applications. Thermoscan, Inc, California.

[6] Rose, L.J., 1999. Ultrasonic Wave in Solid Media, Cambridge University Press, Boston.

[7] Cheeke, J. David N. 2002. Fundamentals and Applications of Ultrasonic Waves. CRC Press

[8] Agbossou, Kodjo, \& Dion, Jean-Luc, \& Carignan, Syvain, \& Abdelkrim, Meftah, \& Cheriti, Ahmed. (2000). Class D Amplifier for a Power Piezoelectric Load. IEEE Transactions on Ultrasonics, Ferroelectrics, and Frequecy

[9] Fuchs, F. John. Ultrasonic Cleaning: Fundamental Theory and Application.Blackstoney Ultrasonic

[10] Sukarno, 2010 Ultrasonic Genertor dengan Frekuensi $100 \mathrm{Khz}$ dan Daya 100 Watt menggunakan Mikrokontroller AVR Attiny 2313. 